\title{
Comprehensive Evaluation Research on Safety Performance of China's Existing Residential Buildings under the Influence of Non-natural Forces

\author{
XUE TING WANG QUN
}

(Xi'an Eurasia University, Xi'an, Shaanxi 710061)

\begin{abstract}
Key words: Non-natural forces; existing residential buildings; safety performance; fuzzy comprehensive evaluation

Abstract: As residential building is one of China's special commodities, its safety should be given top priority. However, there is no professional method for safety performance evaluation of residential buildings up to now. Based on a new safety influence factor evaluation index system for existing residential buildings, and a fuzzy comprehensive evaluation method, this paper evaluates the safety performance of existing residential buildings in a feasible, scientific way, and truly reflects safety performance of China's existing residential buildings, providing certain scientific basis for evaluation of existing residential buildings' safety performance for the government, developers and residents.
\end{abstract}

\section{Introduction}

In a narrow sense, residential building safety refers to the security of residential structure, and reasonable residential structure design indicates good safety performance. However, safety performance of a residential building depends on safety and reliability of its structure, as well as its compliance with requirements of fire prevention and seismic resistance, but also is related to gas safety, electrical safety, daily safety precautions, and hazardous substances. China has strict evaluation criteria for structure safety, fire prevention and anti-seismic grades of residential buildings, but has no professional evaluation method for factors affecting the safety performance of residential buildings such as gas safety, electrical safety, water environment safety, routine safety and precautions. What's more, current safety evaluation of residential buildings is conducted only in accordance with the engineering design acceptance standards which involve excessive indicators. Therefore, to build a scientific, feasible safety influence factor evaluation index system for existing residential buildings under the influence of non-natural forces, and to explore operational safety performance evaluation methods for residential buildings subject to influence of non-natural forces, are of positive and practical significance.

Establishment of the safety performance evaluation index system for existing residential buildings subject to influence of non-natural forces

\section{Safety performance influence factors for residential buildings subject to influence of non-natural forces}

(1) Structural safety

If structural design of a building fails to meet requirements, it will be very insecure. In recent years, many structural safety accidents have happened in China, making people doubt about the safety of structure. However, poor housing quality and even collapse accidents in successive years are not occasional. In the 1990s, China embraced a new round of rapid economic construction, and some residential buildings had good quality, but overall quality of buildings in China was less than satisfactory. At the end of the "Seventh Five-Year Plan" period, quality passing rate stood at 62\%; at the end of the "Eighth Five-Year Plan" period, quality passing rate reached 82\%; at the end of the "Ninth Five-Year Plan" period, quality passing rate rose to $92 \%$, indicating an increase by $30 \%$, but still nearly $1 / 10$ of total projects had inferior quality ${ }^{[1]}$. To seek for interests, some individuals or groups always take a risk to sacrifice structural safety. Therefore, structural safety is the most important factor of affecting safety performance of residential buildings. 


\section{(2) Fire safety}

Fire is another important influence factor for safety performance of a residential building. Due to the unpredictability of fire, China resorts to the means "prevention first, relief supplemented" for fire protection of residential buildings. In this regard, such factors of a building as layer number, plane layout, fire resistance rating, and surrounding environment, should be taken into account.

(3) Safety of gas and electrical equipment

1) Gas safety

Currently, China's urban gas industry is developing rapidly. In particular, along with the completion and operation of a series of gas projects represented by West-East natural gas transmission project, pipeline gas including natural gas, liquefied gas and coal gas has been rapidly popularized in China. Consumption of bottled liquefied gas also increases continually ${ }^{[2]}$. On one hand, the popularity of gas stimulates rapid economic growth, and improves the life quality of residents, reducing environmental pollution. On the other hand, frequent occurrence of gas accidents highlights the gas safety, making gas safety become the greatest concern of gas industry. For example, on December 21, 2005, a natural gas leakage accident occurred in a dormitory rented by Bauhinia Hotel in Yuyang District, Yulin City, Shaanxi Province for its male staff. This accident caused serious casualties due to poisoning including seven deaths and 14 injuries in the same dormitory.

More and more gas accidents prove that gas safety has become another important factor affecting the residential buildings. Gas safety is directly related to personal and property safety of residents, and gas safety influence factors mainly include gas leakage, inadequate combustion, poor ventilation, improper use of gas appliances, and weak safety awareness.

2) Safety of electrical equipment

Along with economic development and improvement of people's living standards, all kinds of electrical appliances have been popularized among residents, while frequent occurrence of various home appliance accidents has made home appliance security become another important factor for safety of a residential building. The main factors that influence safety of electrical equipment include safety of electrical products and materials, as well as security of power supply circuit design.

(4) Safety of water environment

Water is the life source of human, and also one of the resources which people contact most frequently in daily life. Water environment of a residential building covers the systems of drinking water, landscape water and reclaimed water. On July 1, 2007, national mandatory Standards for Drinking Water Quality jointly issued the Standardization Administration of the People's Republic of China and the Ministry of Health was officially implemented. For the first time in 21 years, the original national standard was revised, and pages of drinking water quality indicators increased to 106 from the initial $35^{[3]}$. New national standard stipulates that really safe drinking water cannot contain pathogenic microorganisms, and chemical and radioactive substances, which will harm human health, and its sensory properties should be good.

(5) Daily precautions

Although overall public security situation of China is good, burglary events still happen from time to time. Significant effect has been achieved through property management and installation of antitheft facilities. Specific preventive measures are as follows:

1) Peripheral prevention system

The areas without entrance or exit surrounding the community shall be monitored and managed to prevent the illegal invasion. The range, location and surrounding environment of the community decide the way of setting the peripheral prevention system and supervising. The computer system of 24-hour monitoring of surrounding areas, enables property management personnel of the community to quickly understand the actual situation of surroundings, and automatically gives an alarm and records in case of any illegal intrusion.

2) Access management system

Community access management system will manage and monitor main access passageways, 
parking lots, public places, entrances and exits to residential units. To ensure easy access of community residents, outsiders are subject to limited license access. Monitoring equipment should be installed around the parking lots.

3) Household video intercom system

Household prevention mainly aims to ensure security of private residential buildings and prevent occurrence of burglary/robbery and other serious cases. Household prevention is the most difficult link of security precaution in the community.

(6) Antiskid and anti-fall measures

For pursuit of beautiful external appearance, many residential buildings are decorated with decorative tiles, marble and so on. In case of any fall due to improper design or construction, or long years out of repair, it might cause great security threat to the residents in the community. In addition, bonsai and objects on high windowsills can be easily blown off, which will injure pedestrians. Specific precaution measures include: railing heights of balconies, staircases and parapets, and vertical railing spacing, should meet regulatory requirements; indoor and outdoor decorations should be firm; anti-fall measures should be taken to put things on high places outdoor.

Safety evaluation index system for residential buildings subject to the influence of non-natural forces

According to the security features of non-natural forces for residential buildings, the indicators of electrical equipment safety, gas safety, water safety, anti-skid and anti-fall measures and daily preventive measures, are divided into three levels, i.e., target (A), index (B) and criterion (C).

See Table 1 for the safety evaluation index system for residential buildings subject to the influence of non-natural forces.

Table 1

Safety Evaluation Index System for Residential Buildings Subject to the Influence of Non-natural Forces

\begin{tabular}{|c|c|c|}
\hline \multirow{9}{*}{$\begin{array}{l}\text { Residence } \\
\text { safety } \\
A\end{array}$} & \multirow{6}{*}{$\begin{array}{l}\text { Electrical } \\
\text { equipment } \\
\text { safety } \\
B_{1}\end{array}$} & $\begin{array}{l}\text { 1. Electrical products and materials must conform to current } \\
\text { technical standards } c_{11}\end{array}$ \\
\hline & & $\begin{array}{l}\text { 2. Switches and sockets with regular covers and clean surfaces } \\
\text { should be installed firmly and properly, and be made clung to } \\
\text { walls without gap around, and switches and sockets in the same } \\
\text { room should be installed at the same height } c_{12}\end{array}$ \\
\hline & & $\begin{array}{l}\text { 3. Concealed electrical wiring is favored; there should be no } \\
\text { joint or kinking on the wires in the pipe; the distance between } \\
\text { wire and telephone line/cable TV line should not be less than } \\
50 \mathrm{~cm} \text {; there should be no exposed wires in the suspended } \\
\text { ceiling; wires cannot be directly embedded into the floated coat. } \\
c_{13}\end{array}$ \\
\hline & & $\begin{array}{l}\text { 4. Make lamp caps and wire switches correctly, and choose } \\
\text { moisture-proof switches and safety sockets for toilet and } \\
\text { bathroom. } c_{14}\end{array}$ \\
\hline & & $\begin{array}{l}\text { 5. Anticreeping switches should be installed properly and used } \\
\text { normally. } c_{15}\end{array}$ \\
\hline & & $\begin{array}{l}\text { 6. Weak current system should have complete functions and } \\
\text { meet use requirements, and appliances should be installed } \\
\text { firmly and evenly. } c_{16}\end{array}$ \\
\hline & \multirow{3}{*}{$\begin{array}{l}\text { Gas safety } \\
B_{2}\end{array}$} & $\begin{array}{l}\text { 1. Gas pipelines and other gas equipment in the residence } \\
\text { should meet the current national standard Code for Design of } \\
\text { City Gas Engineering (GB50028-93). (GB50028-93) } c_{21}\end{array}$ \\
\hline & & $\begin{array}{l}\text { 2. The installation place for gas appliances should have good } \\
\text { ventilation conditions. } c_{22}\end{array}$ \\
\hline & & 3. Gas pressure should be normal under \\
\hline
\end{tabular}




\begin{tabular}{|c|c|}
\hline & conditions. $c_{23}$ \\
\hline & 4. Gas should be fully combusted. $c_{24}$ \\
\hline & $\begin{array}{l}\text { 5. Burning appliances should be equipped with flameout } \\
\text { protection devices. } c_{25}\end{array}$ \\
\hline $\begin{array}{l}\text { Water } \\
\text { safety } B_{3}\end{array}$ & $\begin{array}{l}\text { Comply with existing national Standards for Drinking Water } \\
\text { Quality (GB5749-2006) } c_{31}\end{array}$ \\
\hline \multirow{4}{*}{$\begin{array}{l}\text { Anti-skid } \\
\text { and } \\
\text { anti-fall } \\
\text { measures } \\
B_{4}\end{array}$} & $\begin{array}{l}\text { 1. Railing heights of balconies, staircases and parapets, and also } \\
\text { vertical railing spacing should meet the regulatory requirements. } \\
c_{41}\end{array}$ \\
\hline & 2. Indoor and outdoor decorations should be firm. $c_{42}$ \\
\hline & $\begin{array}{l}\text { 3. Ground surfaces of kitchens and bathrooms should be } \\
\text { anti-slip. } c_{43}\end{array}$ \\
\hline & $\begin{array}{l}\text { 4. Anti-fall protection measures should be taken for indoor or } \\
\text { outdoor objects put high. } c_{44}\end{array}$ \\
\hline \multirow{4}{*}{$\begin{array}{l}\text { Daily } \\
\text { preventive } \\
\text { measures } \\
B_{5}\end{array}$} & $\begin{array}{l}\text { 1. Video monitoring system should be installed for monitoring } \\
\text { of entrances and exits, and surrounding areas. } c_{51}\end{array}$ \\
\hline & $\begin{array}{l}\text { 2. Video intercom system and access control system should be } \\
\text { installed. } c_{52}\end{array}$ \\
\hline & $\begin{array}{l}\text { 3. The system for monitoring of public facilities should be } \\
\text { installed. } c_{53}\end{array}$ \\
\hline & $\begin{array}{l}\text { 4. The household security and emergency call and alarm system } \\
\text { should be installed. } c_{54}\end{array}$ \\
\hline
\end{tabular}

\section{Comprehensive safety performance evaluation model for existing residential buildings subject to influence of non-natural forces}

\section{Modeling}

\section{Evaluation level}

According to the principle of fuzzy comprehensive evaluation, and the analytic hierarchy process (AHP), we constructed a hierarchical model for safety evaluation of residential buildings subject to influence of non-natural forces, and defined five safety levels, i.e., Excellent, Good, Medium, Pass and Fail. Corresponding scores of evaluation indicators are determined by the equation $S=\left\{s_{1}, s_{2}, \mathrm{~L}, s_{m}\right\}=\{90,80,70,60,40\}$.

\section{Establishment of a weight set $W$}

Supposing $W$ is the fuzzy weight matrix of influence factors, we determined the weighting coefficients of various indicators through AHP. For example, the weight vector of third-grade indicators over second-grade indicators is subject to the equation $W_{j}=\left\{w_{j_{1}}, w_{j_{2}}, \ldots, w_{j i}\right\}$, and the weight vector of second-grade indicators over first-grade indicators is subject to the equation ${ }^{[4,5]}$ $W=\left\{w_{1}, w_{2}, \ldots, w_{s}\right\}$. In addition, $\sum_{i=1}^{n} w_{j i}=1$, and $\sum_{s=1}^{n} w_{s}=1$.

\section{Determining weights of all factors}

Weight determining is critical to fuzzy comprehensive evaluation, as it directly affects the results of evaluation ${ }^{[6]}$. The general practice is that experts determine weights by experience, but it cannot reflect the objective reality sometimes due to subjectivity and individual difference. Therefore, we introduced AHP to eliminate defects. Specific steps are as follows:

(1) Establish a hierarchical structure, as shown in Table 1.

(2) Construct the pairwise judgment matrix A, and conduct one-time test. In the formula 
$A=\left(a_{i j}\right), a_{i j}$ is an importance scale for comparison of element $i$ and element $j$. See Table 2 for scale defining.

Table 2

Definitions of Judgment Matrix Scale

\begin{tabular}{|l|l|}
\hline Scale value & Meaning \\
\hline 1 & $\begin{array}{l}\text { Two elements are equally important } \\
\text { The former element is slightly more important than } \\
\text { the latter }\end{array}$ \\
\hline 5 & $\begin{array}{l}\text { The former element is obviously important than the } \\
\text { latter }\end{array}$ \\
\hline 7 & $\begin{array}{l}\text { The former element is significantly important than } \\
\text { the latter }\end{array}$ \\
\hline 9 & $\begin{array}{l}\text { The former element is extremely important than the } \\
\text { latter }\end{array}$ \\
\hline $2,4,6,8$ & Mean values of above judgments \\
\hline Reciprocal & The latter element is more important than the former \\
\hline
\end{tabular}

(3) Relative importance vector of normalization of each element over certain former element $W_{i}^{o}$.

$W_{i}=\left(\prod a_{i j}\right)^{\frac{1}{n}}$
$\mathrm{~W}_{\mathrm{i}}^{0}=\frac{\mathrm{W}_{\mathrm{i}}}{\sum_{\mathrm{i}} \mathrm{W}_{\mathrm{i}}}$

(4) Consistency check

(1) Calculating consistency index $C I$

C.I. $=\frac{\lambda_{\max }-n}{n-1}$

$\lambda_{\max }=\frac{1}{n} \sum_{i=1}^{m} \frac{(E W)_{i}}{W_{i}}$

(2) See Table 3 for average random consistency index $R I$.

Table 3 Average Random Consistency Index $R I$

\begin{tabular}{|l|l|l|l|l|l|l|l|l|l|l|l|l|}
\hline$n$ & 1 & 2 & 3 & 4 & 5 & 6 & 7 & 8 & 9 & 10 & 11 & 12 \\
\hline$R I$ & 0 & 0 & 0.52 & 0.89 & 1.12 & 1.26 & 1.36 & 1.41 & 1.46 & 1.49 & 1.52 & 1.54 \\
\hline
\end{tabular}

(3) Calculating the consistency ratio $C R=C I / R I$

If $C R \leq 0.1$, it is generally believed that the consistency of $\mathrm{A}$ is acceptable.

\section{Secondary fuzzy comprehensive evaluation}

(1) Single-stage fuzzy comprehensive evaluation first

$C_{j}=\left[\begin{array}{cccc}r^{j}{ }_{11} & r^{j}{ }_{12} & \mathrm{~L} & r^{j}{ }_{1 p} \\ r^{j}{ }_{21} & r^{j}{ }_{22} & \mathrm{~L} & r^{j}{ }_{2 p} \\ \mathrm{~L} & \mathrm{~L} & \mathrm{~L} & \mathrm{~L} \\ r^{j}{ }_{t 1} & r^{j}{ }_{t 2} & \mathrm{~L} & r^{j}{ }_{t p}\end{array}\right]_{t \times p}$

Single factor fuzzy evaluation object of $B_{i}$ is fuzzy subset, wherein, membership $r_{t p}$ is the ratio between evaluation result and total number of people.

Single-stage model: 


$$
W_{j} C_{j}=\left\{w_{j 1}, \quad w_{j 2}, \mathrm{~L}, w_{j t}\right\} \bullet\left[\begin{array}{cccc}
r^{j}{ }_{11} & r^{j}{ }_{12} & \mathrm{~L} & r^{j}{ }_{1 p} \\
r^{j}{ }_{21} & r^{j}{ }_{22} & \mathrm{~L} & r^{j}{ }_{2 p} \\
\mathrm{~L} & \mathrm{~L} & \mathrm{~L} & \mathrm{~L} \\
r^{j}{ }_{t 1} & r^{j}{ }_{t 2} & \mathrm{~L} & r^{j}{ }_{t p}
\end{array}\right]=\widetilde{B}_{j}(\mathrm{j}=1,2 \cdots 5)
$$

(2) Based on composite factor $B_{i}$, and single-factor evaluation result $\widetilde{B}_{j}$, obtain the affiliation matrix below.

$$
R_{A}=\left[\begin{array}{c}
\widetilde{B}_{1} \\
\widetilde{B}_{2} \\
\widetilde{B}_{3} \\
\tilde{B}_{4} \\
\widetilde{B}_{5}
\end{array}\right]=\left[\begin{array}{ccccc}
r_{11} & r_{12} & r_{13} & r_{14} & r_{15} \\
r_{21} & r_{22} & r_{23} & r_{24} & r_{25} \\
r_{31} & r_{32} & r_{33} & r_{34} & r_{35} \\
r_{41} & r_{42} & r_{43} & r_{44} & r_{45} \\
r_{51} & r_{52} & r_{53} & r_{54} & r_{55}
\end{array}\right]
$$

Secondary fuzzy comprehensive evaluation model

$$
W R_{A}=\left\{w_{1}, w_{2}, w_{3}, w_{4}, w_{5}\right\} \bullet\left[\begin{array}{ccccc}
r_{11} & r_{12} & r_{13} & r_{14} & r_{15} \\
r_{21} & r_{22} & r_{23} & r_{24} & r_{25} \\
r_{31} & r_{32} & r_{33} & r_{34} & r_{35} \\
r_{41} & r_{42} & r_{43} & r_{44} & r_{45} \\
r_{51} & r_{52} & r_{53} & r_{54} & r_{55}
\end{array}\right]=\left(b_{1}, b_{2}, b_{3}, b_{4}, b_{5}\right)=\tilde{B}_{A}
$$

Fuzzy judgment matrix $R_{A}$ of target layer $A$ can be finally obtained by fuzzy judgment of criterion layer, so that comprehensive evaluation result $\widetilde{B}_{A}$ of layer $A$ can be calculated.

Normalized processing:

$$
\tilde{B}_{A}^{\prime}=\left(b_{1} / \sum_{i=1}^{m} b_{i} b_{2} / \sum_{i=1}^{m} b_{i}, \mathrm{~L}, b_{m} / \sum_{i=1}^{m} b_{i}\right)
$$

\section{Comprehensive evaluation criteria}

$$
P_{A}=\tilde{B}_{A}^{\prime} \times S=\sum_{i=1}^{m} b_{i} \times s_{i}
$$

Safety evaluation criteria for residential buildings subject to the influence of non-natural forces are as shown in Table 2. We can determine the housing safety level of a community according to $P_{A}$ and Table 2.

Table 4 Residence Safety Evaluation Criteria

\begin{tabular}{|l|l|l|l|l|l|}
\hline Scores & $P_{A}<60$ & $60 \leq P_{A}<70$ & $70 \leq P_{A}<80$ & $80 \leq P_{A}<90$ & $P_{A} \geq 90$ \\
\hline Level & Fail & Pass & Medium & Good & Excellent \\
\hline
\end{tabular}

\section{Empirical analysis}

We evaluated the safety performance of a residential district in the southern suburbs of Xi'an, under the influence of non-natural forces. We solicited the opinions of the residents in the community by questionnaires and other methods, recovering $90 \%$ of total 200 questionnaires distributed. By fuzzy statistical method, we determined the third-grade index membership $r_{i p}^{j}$ of the community, as shown in Table 3. 
Table 5

\begin{tabular}{|c|c|c|c|c|c|}
\hline $\begin{array}{l}\text { Third-grade } \\
\text { indexes }\end{array}$ & $\begin{array}{l}\text { Excellent } \\
(90)\end{array}$ & $\begin{array}{l}\text { Good } \\
(80)\end{array}$ & $\begin{array}{l}\text { Medium } \\
\text { (70) }\end{array}$ & $\operatorname{Pass}(60)$ & Fail(40) \\
\hline$c_{11}$ & 0.30 & $\begin{array}{ll} & 0.4 \\
0 & \\
\end{array}$ & 0.20 & 0.10 & 0.00 \\
\hline$c_{12}$ & 0.20 & $\begin{array}{ll} & 0.3 \\
0 & \\
\end{array}$ & 0.30 & 0.15 & 0.05 \\
\hline$c_{13}$ & 0.10 & $\begin{array}{ll} & 0.4 \\
0 & \\
\end{array}$ & 0.40 & 0.10 & 0.00 \\
\hline$c_{14}$ & 0.20 & $\begin{array}{ll} & 0.2 \\
0 & \\
\end{array}$ & 0.40 & 0.10 & 0.10 \\
\hline$c_{15}$ & 0.20 & $\begin{array}{ll} & 0.2 \\
0 & \\
\end{array}$ & 0.40 & 0.20 & 0.00 \\
\hline$c_{16}$ & 0.22 & $\begin{array}{ll} & 0.2 \\
8 & \\
\end{array}$ & 0.40 & 0.05 & 0.05 \\
\hline$c_{21}$ & 0.20 & $\begin{array}{ll} & 0.4 \\
0 & \\
\end{array}$ & 0.20 & 0.20 & 0.00 \\
\hline$c_{22}$ & 0.20 & $\begin{array}{ll} & 0.2 \\
0 & \\
\end{array}$ & 0.20 & 0.25 & 0.15 \\
\hline$c_{23}$ & 0.10 & $\begin{array}{ll} & 0.3 \\
0 & \\
\end{array}$ & 0.20 & 0.25 & 0.15 \\
\hline$c_{24}$ & 0.20 & $\begin{array}{ll} & 0.2 \\
0 & \\
\end{array}$ & 0.20 & 0.20 & 0.20 \\
\hline$c_{25}$ & 0.20 & $\begin{array}{ll} & 0.3 \\
0 & \\
\end{array}$ & 0.10 & 0.30 & 0.10 \\
\hline$c_{31}$ & 0.30 & $\begin{array}{ll} & 0.2 \\
0 & \\
\end{array}$ & 0.30 & 0.19 & 0.01 \\
\hline$c_{41}$ & 0.30 & $\begin{array}{ll} & 0.3 \\
0 & \\
\end{array}$ & 0.20 & 0.20 & 0.00 \\
\hline$c_{42}$ & 0.20 & $\begin{array}{ll} & 0.2 \\
0 & \end{array}$ & 0.20 & 0.25 & 0.15 \\
\hline$c_{43}$ & 0.10 & $\begin{array}{ll} & 0.2 \\
0 & \\
\end{array}$ & 0.30 & 0.30 & 0.10 \\
\hline$c_{44}$ & 0.00 & $\begin{array}{ll} & 0.1 \\
0 & \\
\end{array}$ & 0.40 & 0.30 & 0.20 \\
\hline$c_{51}$ & 0.10 & $\begin{array}{ll} & 0.2 \\
0 & \\
\end{array}$ & 0.30 & 0.20 & 0.20 \\
\hline$c_{52}$ & 0.10 & $\begin{array}{ll} & 0.2 \\
0 & \\
\end{array}$ & 0.30 & 0.20 & 0.20 \\
\hline$c_{53}$ & 0.20 & $\begin{array}{ll} & 0.2 \\
0 & \\
\end{array}$ & 0.30 & 0.20 & 0.10 \\
\hline$c_{54}$ & 0.05 & $\begin{array}{ll} & 0.1 \\
5 & \end{array}$ & 0.30 & 0.20 & 0.30 \\
\hline
\end{tabular}

(1) Determining the third-grade index weight vector $W_{i}$ and second-grade index weight vector $W$ of the community

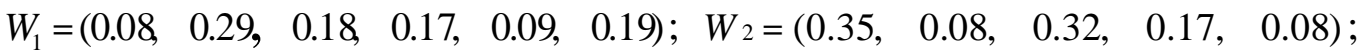

$$
\begin{aligned}
& W_{3}=(1) ; W_{4}=\left(\begin{array}{llll}
0.48, & 0.28, & 0.12, & 0.12
\end{array}\right) ; W_{5}=\left(\begin{array}{llll}
0.37, & 0.17, & 0.37, & 0.09
\end{array}\right) \text {; } \\
& W=\left(\begin{array}{llll}
0.36 & 0.36, \quad 0.15, & 0.08, \quad 0.05
\end{array}\right) \text {. }
\end{aligned}
$$

(2) Fuzzy membership matrix $C_{j}$ of third-grade index over second-grade index can be obtained according to Table 4: 


$$
\begin{aligned}
C_{1} & =\left[\begin{array}{lllll}
0.30 & 0.40 & 0.20 & 0.10 & 0.00 \\
0.20 & 0.30 & 0.30 & 0.15 & 0.05 \\
0.10 & 0.40 & 0.40 & 0.10 & 0.00 \\
0.20 & 0.20 & 0.40 & 0.10 & 0.10 \\
0.20 & 0.20 & 0.40 & 0.20 & 0.00 \\
0.22 & 0.28 & 0.40 & 0.05 & 0.05
\end{array}\right] ; C_{2}=\left[\begin{array}{lllll}
0.20 & 0.40 & 0.20 & 0.20 & 0.00 \\
0.20 & 0.20 & 0.20 & 0.25 & 0.15 \\
0.10 & 0.30 & 0.20 & 0.25 & 0.15 \\
0.20 & 0.20 & 0.20 & 0.20 & 0.20 \\
0.20 & 0.30 & 0.10 & 0.30 & 0.10
\end{array}\right] \\
C_{3} & =\left[\begin{array}{lllll}
0.30 & 0.20 & 0.30 & 0.19 & 0.01
\end{array}\right] ; C_{4}=\left[\begin{array}{lllll}
0.30 & 0.30 & 0.20 & 0.20 & 0.00 \\
0.20 & 0.20 & 0.20 & 0.25 & 0.15 \\
0.10 & 0.20 & 0.30 & 0.30 & 0.10 \\
0.00 & 0.10 & 0.40 & 0.30 & 0.20
\end{array}\right] \\
C_{5} & =\left[\begin{array}{lllll}
0.10 & 0.20 & 0.30 & 0.20 & 0.20 \\
0.10 & 0.20 & 0.30 & 0.20 & 0.20 \\
0.20 & 0.20 & 0.30 & 0.20 & 0.10 \\
0.05 & 0.15 & 0.30 & 0.20 & 0.30
\end{array}\right]
\end{aligned}
$$

(3) Calculating the single-stage index comprehensive evaluation value $\widetilde{B}_{j}$

After calculation according to the equation $\widetilde{B}_{1}=W_{1} C_{1}=(0.20,0.30,0.36,0.10,0.04)$, calculate other secondary indexes according to the equation $\tilde{B}_{j}(\mathrm{j}=2,3,4,5)$, to form the affiliation matrix $R_{A}$ for secondary fuzzy comprehensive evaluation.

$$
R_{A}=\left[\begin{array}{lllll}
0.20 & 0.30 & 0.36 & 0.10 & 0.04 \\
0.17 & 0.31 & 0.19 & 0.23 & 0.10 \\
0.30 & 0.20 & 0.30 & 0.19 & 0.01 \\
0.20 & 0.24 & 0.24 & 0.24 & 0.08 \\
0.13 & 0.20 & 0.30 & 0.20 & 0.17
\end{array}\right]
$$

(4) Calculating comprehensive evaluation membership vector $\tilde{B}_{A}=W R_{A}=(0.20,0.28,0.28,0.18,0.06)$

(5) Score of actual quality level of residential buildings in the community

$$
P_{A}=\tilde{B}_{A}^{\prime} \times S=(0.20,0.28,0.28,0.18,0.06)(90,80,70,60,40)^{\mathrm{T}}
$$

$$
=73.2
$$

Score of actual quality level of residential buildings in the community is 73.2. According to the quality level evaluation criteria as set forth in Table 2, safety level of residential buildings subject to influence of non-natural forces is Medium.

\section{Conclusions}

This paper established a safety performance index system for existing residential buildings subject to influence of non-natural forces, and evaluated the safety of particular residential buildings by fuzzy comprehensive evaluation model, which is scientific and operable to some extent. However, there are many safety performance influence factors, and only representative factors were selected for establishment of the new index system. Other sub-items required in the standards still need further studies. 


\section{References}

[1] Tian Xinzhi. Practices of Commercial Housing Construction Quality Assessment [M]. Zhengzhou: Yellow River Water Conservancy Press, 2014.50-60

[2] Liu Shucheng, Zhang Guoqiang, Bing Pizhong. Cause Analysis of Urban Gas Accidents [J]. Urban Gas, 2012 (5): 14-16

[3] Standardization Administration of the People's Republic of China, the Ministry of Health. Standards for Drinking Water Quality (GB5749-2006). Beijing: China Standards Press, 2015

[4] Chang Dayong, Zhang Lili. Fuzzy Mathematical Method of Economic Management [M] Beijing: Publishing House of School of Economics Peking University, 1995.

[5] Ye Yicheng, Ke Lihua, Huang Deyu. Comprehensive System Evaluation Technology and Its Application [M] Beijing: Metallurgical Industry Press, 2015.

[6] Wang Yingluo. System Engineering [M] Beijing: China Machine Press, 2010.131-137 